\title{
The comparison of nasal surgery and CPAP on daytime sleepiness in patients with OSAS*
}

\author{
Mitsuhiko Tagaya ${ }^{1,2}$, Hironao Otake ${ }^{2}, K^{2}$ eisuke Suzuki2,3, Fumihiko Yasuma4, \\ Hiroshi Yamamoto ${ }^{2,5}$, Akiko Noda ${ }^{6}$, Yoichi Nishimura7, Michihiko Sone², \\ Tsutomu Nakashima², Seiichi Nakata2,7 \\ ' Department of Otorhinolaryngology, Shirakabe clinic, Nagoya, Japan \\ ${ }^{2}$ Department of Otorhinolaryngology, Graduate School of Medicine, Nagoya University, Nagoya, Japan \\ ${ }^{3}$ Department of Otorhinolaryngology, Suzuki ENT clinic, Nagoya, Japan \\ ${ }^{4}$ Department of Internal Medicine, National Hospital Organization Suzuka Hospital, Suzuka, Japan \\ ${ }^{5}$ Department of Otorhinolaryngology, Nagoya Central Hospital, Nagoya, Japan \\ ${ }^{6}$ Department of Biomedical Sciences, Chubu University, Kasugai, Japan \\ ' Department of Otorhinolaryngology, Second Hospital, Fujita Health University School of Medicine, Nagoya, Japan
}

Rhinology 55: 269-273, 2017

https://doi.org/10.4193/Rhino17.026

*Received for publication:

February 5, 2017

Accepted: May 14, 2017

\begin{abstract}
Objective: Residual sleepiness after continuous positive airway pressure (CPAP) is a critical problem in some patients with obstructive sleep apnea syndrome (OSAS). However, nasal surgery is likely to reduce daytime sleepiness and feelings of unrefreshed sleep. The aim of this study is to clarify the effects of nasal surgery and CPAP on daytime sleepiness.
\end{abstract}

Methodology: This is a retrospective and matched-case control study. The participants were consecutive 40 patients with OSAS who underwent nasal surgery (Surgery group) and 40 matched patients who were treated with CPAP (CPAP group).

Results: In the Surgery group, although the nasal surgery did not decrease either apnea or hypopnea, it improved oxygenation, the quality of sleep. In the CPAP Group, the CPAP treatment reduced apnea and hypopnea, and improved oxygenation, quality of sleep. The degree of relief from daytime sleepiness was different between the two groups. The improvement of Epworth Sleepiness Scale was more significant in the Surgery Group than those in the CPAP Group (Surgery from 11.0 to 5.1, CPAP from 10.0 to $6.2)$.

Discussion: These findings suggest that the results of the nasal surgery is more satisfactory for some patients with OSAS than CPAP on daytime sleepiness.

Key words: nasal surgery, obstructive sleep apnea syndrome, oxygenation during sleep, Epworth sleepiness scale, daytime sleepiness

\section{Introduction}

The primary nonsurgical treatment of patients with moderate to severe obstructive sleep apnea syndrome (OSAS) is nasal continuous positive airway pressure (CPAP) ${ }^{(1)}$. Although it is been known that CPAP resolves most respiratory events and that it reduces daytime sleepiness, intolerance to CPAP is found approximately in $40 \%-50 \%$ of patients with OSAS ${ }^{(2,3)}$. This intolerance limits the effectiveness of OSAS treatment. Therefore, residual sleepiness after CPAP is a critical problem in sleep medicine ${ }^{(4-6)}$.
Nasal surgery is likely to decrease nasal obstruction and reduce daytime sleepiness and feelings of unrefreshed sleep, but it is not sufficient to improve sleep apnea ${ }^{(7-9)}$. The major impact of nasal surgery is on relief from subjective symptoms and severity of obstructive events in OSAS, but not in lowering the occurrence of obstructive events ${ }^{(10)}$, and we have already shown that the overall quality of sleep is improved postoperatively ${ }^{(11)}$. Therefore, the aim of this study was to compare daytime sleepiness and sleep quality in patients with OSAS and daytime sleepiness who underwent nasal surgery or were treated with CPAP. 


\section{Patients and methods}

Study design and patients selection

This study was conducted in accordance with the Declaration of Helsinki and approved by our local institutional review board. Informed consent was obtained from all participants. We evaluated the effects of treatment for OSAS using the Epworth Sleepiness Scale (ESS) and polysomnography.

This is a retrospective and matched-case control study. We examined consecutive 40 male patients with OSAS and an apneahypopnea index $(\mathrm{AHI}) \geq 20$ who underwent nasal surgery at the Nagoya University School of Medicine Hospital during a 3-year period from January 2006 to December 2008. These patients suffered from refractory nasal obstruction, and nasopharyngoscopy revealed marked mucosal thickening or a deviated septum. The severity of nasal obstruction was determined by combining the symptoms, rhinomanomerty and endoscopic findings. Subsequently, we retrospectively collected control data from male patients with OSAS under CPAP treatment. CPAP was indicated only when the $A H I$ was $\geq 20$, and 40 such patients were selected as case-matched controls for this study. No patient suffered from nasal obstruction in non-surgical group. All the patients used auto-adjusting CPAP machine. We classified the 40 patient participants with OSAS and $\mathrm{AHI} \geq 20$ who underwent nasal surgery as the Surgery group and the 40 patient participants with OSAS and AHI $\geq 20$ who underwent CPAP treatment as the CPAP group.

\section{Polysomnography}

Standard polysomnography was performed (model Alice 4; Respironics Inc, Murrysville, PA, USA) with electroencephalogram (C3-A2 and C4-A1, O1-A2 and O2-A1), electrooculogram, electromyogram, and electrocardiogram monitoring, and oronasal airflow measured with oronasal thermistors, and thoracoabdominal motion measured with piezo sensors. An apnea was defined as a cessation of airflow through the mouth and nose lasting for $\geq 10 \mathrm{~s}$. Hypopnea was defined as $\mathrm{a} \geq 30 \%$ reduction in airflow with oxygen desaturation on pulse oximetry $\left(\mathrm{SpO}_{2}\right) \geq 3 \%$ or with an arousal lasting for 10s. The apnea index (Al) and $\mathrm{AHI}$ were determined as numbers of apnea and apnea plus hypopnea events per hour respectively. The oxygen desaturation index (ODI) was determined as number of oxygen desaturation $\left(\mathrm{SpO}_{2}\right.$ $\geq 3 \%$ ) events per hour, and the lowest $\mathrm{SpO}_{2}$ was determined.

\section{Rhinomanometry and surgical techniques}

Nasal resistance at $\triangle \mathrm{P} 100 \mathrm{~Pa}$ during inspiration was measured using active anterior rhinomanometry (MPR-3100; Nihon-Kohden, Tokyo, Japan) during daytime wakefulness with the patient in an upright sitting position before and after surgery. Nasal surgery was performed under general anesthesia with endoscopy. The nasal surgery consisted of inferior turbinectomy or submucous resection of the nasal septum (or both) or endosco-
Table 1. Pretreatment characteristics of nasal surgery and CPAP group.

\begin{tabular}{|lccc|}
\hline & Nasal surgery & CPAP & P \\
\hline Number & 40 & 40 & \\
\hline Age (years) & $48.1 \pm 11.3$ & $50.1 \pm 8.9$ & 0.19 \\
\hline BMI (kg/m²) & $26.9 \pm 3.7$ & $28.1 \pm 3.5$ & 0.06 \\
\hline Nasal resistance (Pa/cm $\left.{ }^{3}\right)$ & $0.55 \pm 0.33$ & $0.29 \pm 0.17$ & $<0.01$ * \\
\hline ESS & $11.0 \pm 4.0$ & $10.0 \pm 4.6$ & 0.16 \\
\hline PSG data & & & \\
\hline Apnea index (/hr) & $31.1 \pm 24.5$ & $30.9 \pm 21.4$ & 0.49 \\
\hline $\begin{array}{l}\text { Apnea-hypopnea index } \\
\text { (/hr) }\end{array}$ & $(3.0-81.4)$ & $(1.0-99.9)$ & \\
\hline & $52.6 \pm 18.9$ & $51.2 \pm 17.2$ & 0.36 \\
\hline $\begin{array}{l}\text { Oxygen desaturation } \\
\text { index (/hr) }\end{array}$ & $(20.8-90.8)$ & $(20.2-82.9)$ & \\
\hline & $73.0 \pm 80.1$ & $52.3 \pm 45.5$ & 0.08 \\
\hline Lowest SpO & & & \\
\hline & $(15.0-210.0)$ & $(14.7-224.5)$ & 0.14 \\
\hline
\end{tabular}

Average \pm SD. ${ }^{*} \mathrm{p}<0.05$

pic sinus surgery.

\section{Statistical analysis}

The results are expressed as the means \pm standard error of averaged values. The data were analyzed using a two-sided Student t test, and $\mathrm{P}<0.05$ was considered significant.

\section{Results}

Pretreatment characteristics of patients in the Surgery and CPAP groups are shown in Table 1. Between the groups, age, BMI, and $\mathrm{ESS}, \mathrm{AHI}, \mathrm{ODI}$, and lowest SpO2 in polysomnographic data were not significantly different, but nasal resistance was significantly different $(0.55$ vs 0.29$)$. There is no difference between Surgery and CPAP group in OSAS severity $(\mathrm{p}=0.82)$. All 40 patients had inferior turbinectomy, in addition, 36 patients had resection of nasal septum and 2 patients had endoscopic sinus surgery. Pre- and posttreatment data from patients in the Surgery group are shown in Table 2. After the surgery, ODI, lowest $\mathrm{SpO}_{2^{\prime}}$ REM sleep, stage 2 sleep, and sleep efficacy were improved. However, $\mathrm{Al}, \mathrm{AHI}$ and arousal index were not improved.

Pre- and posttreatment data from patients in the CPAP group are shown in Table 3. Al, $\mathrm{AHI}, \mathrm{ODI}$, lowest $\mathrm{SpO}_{2}$, REM sleep, stage 2 sleep, and arousal index were improved. After the treatment, almost all the PSG data parameters were improved except sleep 
Table 2. Pre and post-treatment data of nasal surgery group.

\begin{tabular}{|c|c|c|c|}
\hline & Pre & Post & $\mathbf{p}$ \\
\hline \multirow{2}{*}{$\begin{array}{l}\text { Nasal resistance } \\
\left(\mathrm{Pa} / \mathrm{cm}^{3}\right)\end{array}$} & $0.55 \pm 0.33$ & $0.18 \pm 0.10$ & $<0.01 *$ \\
\hline & $(0.26-1.50)$ & $(0.10-0.72)$ & \\
\hline ESS & $11.0 \pm 4.0$ & $5.1 \pm 2.3$ & $<0.01 *$ \\
\hline \multicolumn{4}{|l|}{ PSG data } \\
\hline \multirow[t]{2}{*}{ Apnea index (/hr) } & $31.1 \pm 24.5$ & $29.9 \pm 23.2$ & 0.25 \\
\hline & $(3.0-81.4)$ & $(3.7-67.7)$ & \\
\hline \multirow[t]{2}{*}{$\begin{array}{l}\text { Apnea-hypopnea } \\
\text { index (/hr) }\end{array}$} & $52.6 \pm 18.9$ & $49.5 \pm 17.8$ & 0.11 \\
\hline & $(20.8-90.8)$ & $(23.8-101.1)$ & \\
\hline \multirow[t]{2}{*}{$\begin{array}{l}\text { Oxygen desaturation } \\
\text { index (/hr) }\end{array}$} & $73.0 \pm 80.1$ & $53.4 \pm 61.2$ & $<0.01$ * \\
\hline & $(15.0-210.0)$ & $(9.8-200.0)$ & \\
\hline \multirow[t]{2}{*}{ Lowest $\mathrm{SpO}_{2}(\%)$} & $73.4 \pm 10.0$ & $76.9 \pm 7.5$ & $<0.01 *$ \\
\hline & $(51-86)$ & $(60-91)$ & \\
\hline \multicolumn{4}{|l|}{ Sleep stage (\%) } \\
\hline REM & $15.0 \pm 5.0$ & $17.2 \pm 4.8$ & $<0.01 *$ \\
\hline stage 1 & $42.4 \pm 19.5$ & $35.0 \pm 16.1$ & $<0.01 *$ \\
\hline stage 2 & $39.5 \pm 18.0$ & $44.7 \pm 18.0$ & $<0.01 *$ \\
\hline stage $3+4$ & $1.2 \pm 3.2$ & $0.6 \pm 1.5$ & 0.05 \\
\hline Arousal index (/hr) & $42.6 \pm 16.3$ & $41.0 \pm 15.2$ & 0.27 \\
\hline Sleep efficacy (\%) & $86.4 \pm 7.2$ & $88.7 \pm 5.7$ & $0.03 *$ \\
\hline
\end{tabular}

Average $\pm S D .{ }^{*} p<0.05$
Table 3. Pre and post-treatment data of CPAP group.

\begin{tabular}{|c|c|c|c|}
\hline & Pre & Post & $\mathbf{p}$ \\
\hline \multirow[t]{2}{*}{$\begin{array}{l}\text { Nasal resistance } \\
\left(\mathrm{Pa} / \mathrm{cm}^{3}\right)\end{array}$} & $0.29 \pm 0.17$ & $0.27 \pm 0.08$ & 0.17 \\
\hline & $(0.06-0.96)$ & $(0.15-0.38)$ & \\
\hline ESS & $10.0 \pm 4.6$ & $6.2 \pm 3.1$ & $<0.01 *$ \\
\hline \multicolumn{4}{|l|}{ PSG data } \\
\hline \multirow[t]{2}{*}{ Apnea index (/hr) } & $30.9 \pm 21.4$ & $4.5 \pm 9.4$ & $<0.01 *$ \\
\hline & $(1.0-99.9)$ & $(0-29.9)$ & \\
\hline \multirow[t]{2}{*}{$\begin{array}{l}\text { Apnea-hypopnea } \\
\text { index (/hr) }\end{array}$} & $51.2 \pm 17.2$ & $9.6 \pm 12.2$ & $<0.01 *$ \\
\hline & $(20.2-82.9)$ & $(0-32.0)$ & \\
\hline \multirow[t]{2}{*}{$\begin{array}{l}\text { Oxygen desaturation } \\
\text { index (/hr) }\end{array}$} & $52.3 \pm 45.5$ & $6.9 \pm 10.7$ & $<0.01 *$ \\
\hline & $(14.7-224.5)$ & $(0-42.5)$ & \\
\hline \multirow[t]{2}{*}{ Lowest $\mathrm{SpO}_{2}(\%)$} & $75.5 \pm 7.7$ & $88.2 \pm 6.2$ & $<0.01 *$ \\
\hline & $(57-90)$ & $(71-94)$ & \\
\hline \multicolumn{4}{|l|}{ Sleep stage (\%) } \\
\hline REM & $12.4 \pm 5.5$ & $16.4 \pm 6.3$ & $<0.01 *$ \\
\hline stage 1 & $49.8 \pm 20.4$ & $28.0 \pm 12.1$ & $<0.01 *$ \\
\hline stage 2 & $30.0 \pm 17.7$ & $47.6 \pm 13.3$ & $<0.01 *$ \\
\hline stage $3+4$ & $0.3 \pm 0.8$ & $1.0 \pm 4.1$ & 0.15 \\
\hline Arousal index (/hr) & $42.8 \pm 16.1$ & $16.3 \pm 9.8$ & $<0.01 *$ \\
\hline Sleep efficacy (\%) & $73.2 \pm 15.5$ & $74.4 \pm 15.5$ & 0.36 \\
\hline
\end{tabular}

Average \pm SD. ${ }^{*} \mathrm{p}<0.05$ efficacy.

The change in ESS is shown in Figure 1. ESS was decreased both in the Surgery and CPAP groups. ESS was significantly lower in the Surgery group than in the CPAP group (5.1 vs 6.2) $(p<0.01)$. Nasal surgery was superior to CPAP treatment on improvement of daytime sleepiness relief.

\section{Discussion}

Nasal surgery improves ESS score significantly in patients with OSAS ${ }^{(9,11,12)}$, and these sorts of findings ${ }^{(7,8)}$ might be related to an increase in the deeper levels of sleep. Although an improvement of ESS was compared between CPAP and uvulopalatoplasty treatment ${ }^{(13)}$, to our knowledge, subjective daytime sleepiness or the level of daytime alertness, has not been compared after CPAP or nasal surgery treatment.

We performed a case-controlled study of the effects of nasal surgery and CPAP treatment on sleep parameters. Both treatments improved not only respiratory events, but also sleep architecture and quality. In addition, nasal surgery in patients with OSAS substantially improved daytime sleepiness compared with CPAP treatment.

Of course, nasal surgery improved sleep quality including patients without OSAS ${ }^{(14)}$. However, because our study was limited to OSAS patients, the severities at baseline were worse and the improvement of ESS was more greatly in our study than in the study ${ }^{(14)}$.

Daytime sleepiness is reduced by CPAP treatment, but some degree of somnolence remains. Subjective daytime sleepiness in patients with OSAS may be influenced not only by the severity of respiratory disorder indices, but also by certain personality characteristics affecting hypochondriasis score ${ }^{(15)}$ and by persistent obesity ${ }^{(16)}$. In our study, we have not considered psychiatric problems because we selected patients in the Surgery group solely according to otorhinolaryngological findings.

Nasal resistance correlates with $\mathrm{AHI}$ in patients with OSAS and

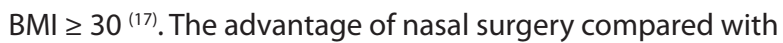
CPAP treatment on daytime sleepiness may be explained, at least in part, as relief from nasal obstruction ${ }^{(17,18)}$. Chronic nasal 


\section{ESS}

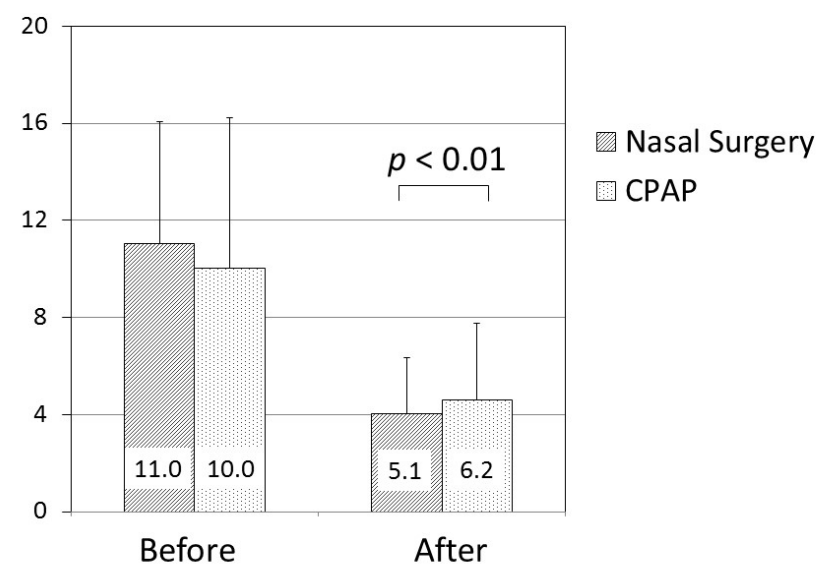

Figure.1 Changes in Epworth Sleepiness Score before and after treatment in Nasal Surgery and CPAP. Nasal surgery was superior to CPAP treatment on improvement of daytime sleepiness relief.

obstruction impairs various daily and social activities, at least in part, through excessive daytime sleepiness possibly caused by sleep-disordered breathing ${ }^{(19)}$. The current study suggests that correction of nasal obstruction by nasal surgery is effective treatment for the relief of daytime sleepiness in some patients with OSAS. We emphasize that nasal surgery is not a substitute for CPAP. It would be interesting to know the results of ESS in pa- tients who had nasal surgery and then tried CPAP for next study. Our study has several weak points. At first, our study is case control study, so the comment to the possibility of selection bias may be persistent. The second, our study had small number in patient population. As a result, the study impact may be regrettably small. The third, daytime aleertness is not explainable only in ESS score. Therefore, the method of assessment in daytime sleepiness is a future consideration.

\section{Conclusion}

To conclude, the effects of nasal surgery and CPAP for treating OSAS are different. Although nasal surgery does not reduce the apnea or hypopnea, it substantially ameliorates symptoms of daytime sleepiness compared with CPAP treatment, which decreases the apnea and hypopnea. These findings suggest that the results of the nasal surgery is more satisfactory for OSAS patients than CPAP according to the daytime sleepiness.

\section{Authorship contribution}

The contribution to the planning and design, acquisition of data was made by MT, HO, KS, HY and SN. The interpretation and analysis of data, drafting and revising of the article was made by all 10 authors.

\section{Conflict of interest}

None

\section{References}

1. American Thoracic Society: Indication and standards for use of nasal continuous positive airway pressure (CPAP) in sleep apnea syndrome. Am J Respir Crit Care Med 1994;150:1738-1745.

2. Kribbs NB, Pack Al, Kline LR, et al. Objective measurement of sleep patterns of nasal CPAP use by patients with obstructive sleep apnea. Am Rev Respir Dis 1993;147:887895.

3. Richard W, Venker J, den Herder C, et al. Acceptance and long-term compliance of nCPAP in obstructive sleep apnea. Eur Arch Otorhinolaryngol 2007;264:1081-1086.

4. Guilleminault C, Phillip P. Tiredness and somnolence despite initial treatment of obstructive sleep apnea syndrome (What to do when an OSAS patient stays hypersomnolent despite treatment). Sleep 1996;19(9 Suppl):S117-122

5. Pépin JL, Viot-Blanc $V$, Escourrou $P$, et al. Prevalence of residual excessive sleepiness in CPAP-treated sleep apnoea patients: the French multicentre study. Eur Respir J 2009;33:1062-1067.

6. Gasa M, Tamisier R, Launois SH, et al. Residual sleepiness in sleep apnea patients treated by continuous positive airway pres- sure. J Sleep Res 2013;22:389-397.

7. Li HY, Lee LA, Wang PC, et al. Nasal surgery for snoring in patients with obstructive sleep apnea. Laryngoscope 2008;118:354359.

8. Sufioğlu M1, Ozmen OA, Kasapoglu F, et al. The efficacy of nasal surgery in obstructive sleep apnea syndrome: a prospective clinical study. Eur Arch Otorhinolaryngol 2012;269:487-494.

9. Ishii L, Roxbury C, Godoy A, Ishman S, Ishii $M$. Does nasal surgery improve OSA in patients with nasal obstruction and OSA? A meta-analysis. Otolaryngol Head and Neck Surg 2015:153:326-333.

10. Li HY, Lee LA, Wang PC, Fang TJ, Chen NH. Can nasal surgery improve obstructive sleep apnea: subjective or objective? Am J Rhinol Allergy 2009;23:e51-55.

11. Nakata S, Noda A, Yasuma F, et al. Effects of nasal surgery on sleep quality obstructive sleep apnea syndrome with nasal obstruction. Am J Rhinol 2008;22:59-63.

12. Hisamatsu K, Kudo I, Makiyama K. The effects of compound nasal surgery on obstructive sleep apnea syndrome. Am J Rhinol 2015;29:e192-196.

13. Lin SW, Chen NH, Li HY, et al. A comparison of the long-term outcome and effects of surgery or continuous positive airway pressure on patients with obstructive sleep apnea syndrome. Laryngoscope 2006;116:1012-1026.

14. Stapleton AL, Chang YF, Soose RJ, Gillman GS. The impact of nasal surgery on sleep quality: a prospective outcomes study. Otolaryngol Head and Neck Surg 2014:151:868-873.

15. Kousourelakis I, Perraki E, Economou NT, et al. Predictors of residual sleepiness in adequately treated obstructive sleep apnoea patients. Eur Respir J 2009;34:687-693.

16. Morisson F, Décary A, Petit D, Lavigne G, Malo J, Montplaisir J. Daytime sleepiness and EEG spectral analysis in apneic patients before and after treatment with continuous positive airway pressure. Chest 2001;119:45-52

17. Tagaya M, Nakata S, Yasuma F, et al. Pathogenetic role of increased nasal resistance in obese patients with obstructive sleep apnea syndrome. Am J Rhinol Allergy 2010;24:51-54.

18. Li HY, Lin Y, Chen NH, et al. Improvement in quality of life after nasal surgery alone for patients with sleep apnea and nasal obstruction. Arch Otolaryngol Head Neck Surg 2008;134:429-433. 
19. Choi JH, Kim EJ, Kim YS, et al. Effectiveness of nasal surgery alone on sleep quality, architecture, position, and sleep-disordered breathing in obstructive sleep apnea syndrome with nasal obstruction. Am J Rhinol Allergy 2011;25:338-441.

20. Udaka T, Suzuki H, Kitamura T, et al. Relationships among nasal obstruction, daytime sleepiness, and quality of life. Laryngoscope 2006;116:2129-2132.
Mitsuhiko Tagaya

Department of Otorhinolaryngology

Shirakabe clinic

1-2-1 Yoshino, Higashi

Nagoya, 461-0027

Japan

Tel: +81-52-936-8733

E-mail:mi-man@ra2.so-net.ne.jp 